\title{
Syntactic priming in written production: Evidence for rapid decay
}

\author{
HOLLY P. BRANIGAN, MARTIN J. PICKERING, and ALEXANDRA A. CLELAND \\ University of Glasgow, Glasgow, Scotland
}

\begin{abstract}
There is strong evidence for syntactic priming in language production (Bock, 1986), but little evidence about the time course of such effects. We report an experiment that examined the circumstances under which syntactic priming decays in written language production. Participants completed sentence fragments that allowed completions with one of two syntactic forms (Pickering \& Branigan, 1998). They tended to produce the same syntactic form for immediately consecutive fragments, even though the two fragments described different events. However, when the experimental fragments were separated by other fragments with unrelated syntactic forms, this tendency rapidly diminished. The results suggest that priming effects in written production decay rapidly when other structures are subsequently produced. We discuss the implications for the application of syntactic information during production.
\end{abstract}

A tendency to repeat syntactic structure during language production has been noted in dialogue (Estival, 1985; Giles \& Powesland, 1975; Levelt \& Kelter, 1982; Schenkein, 1980; Tannen, 1989; Weiner \& Labov, 1983) and in the production of isolated sentences in speech (Bock, 1986, 1989; Bock \& Loebell, 1990; Bock, Loebell, \& Morey, 1992; Potter \& Lombardi, 1998) and writing (Pickering \& Branigan, 1998). Bock (1986) showed that the structure of picture descriptions was affected by the structure of a previous sentence. Under the guise of a memory test, participants repeated sentences like the following:

The rock star sold some cocaine to an undercover agent.

The rock star sold an undercover agent some cocaine.

Examples $1 \mathrm{a}$ and $1 \mathrm{~b}$ describe the same situation, but involve different syntactic structures: In la, the verb sold is followed by a noun phrase (some cocaine) and a prepositional phrase (to an undercover agent); in $1 \mathrm{~b}$, the verb is followed by two noun phrases (an undercover agent and some cocaine). We call la a prepositional object (PO) sentence and $1 \mathrm{~b}$ a double object (DO) sentence. Participants then saw a picture that could be described using a PO or a DO construction (e.g., a girl handing a paintbrush to a man). The prime was not semantically re-

The order of the first two authors is arbitrary. We thank Stuart Boutell and Andrew Stewart for their assistance. This research was supported by a British Academy Postdoctoral Fellowship (awarded to H.P.B.) and ESRC Research Grant R000237418. Correspondence should be addressed to $\mathrm{H}$. P. Branigan, Human Communication Research Centre, Department of Psychology, University of Glasgow, Florentine House, 53 Hillhead Street, Glasgow G12 8QF, Scotland (e-mail: holly@psy.gla.ac.uk). lated to the target picture, and the prime and target did not form a connected discourse. The form of the prime affected the form of the target description. Participants were more likely to produce a PO sentence like The girl handed a paintbrush to the man. after a PO prime than after a DO prime, and more likely to produce a DO sentence like The girl handed the man a paintbrush. after a DO prime than after a PO prime. Bock (1986) also found priming effects with active and passive sentences. Subsequent experiments excluded explanations in terms of lexical, thematic, or metrical correspondences between prime and target sentences (Bock, 1989; Bock \& Loebell, 1990; Bock et al., 1992). Instead, they appear to arise from correspondences at a syntactic level. Similar effects have been found in spoken sentence recall (Potter \& Lombardi, 1998) and written sentence completion (Pickering \& Branigan, 1998).

Bock and Loebell (1990) accounted for these effects in a manner that is consistent with Levelt's (1989) model of language production. This model identifies three components of processing: conceptualization (generating a message to be communicated); formulation (encoding the message in linguistic form); and articulation (realizing this form as speech or writing). Bock and Loebell suggested that one subcomponent of formulation involves activation of syntactic procedures. Each procedure is associated with the activation of a particular syntactic form (characterized in terms of phrase structure). For example, producing Example la would involve the activation of the procedure associated with a PO structure, whereas producing $1 \mathrm{~b}$ would involve the activation of the procedure associated with a DO structure. They assumed that priming occurs because activation of a procedure persists after an initial sentence has been produced, and thus the likelihood of applying the same procedure in production of the subsequent sentence is increased. (An alternative possibility that is equally consistent with the evidence is that producing a sentence in- 
volves activation of grammatical knowledge; see Branigan, Pickering, Liversedge, Stewart, \& Urbach, 1995, for discussion.)

One question this raises is the manner in which the residual activation that is assumed to underlie syntactic priming decays. On the one hand, priming of a procedure might persist until the language user employs an alternative procedure that can express the same message as the primed procedure. For example, if a message can be described with a PO or a DO structure (and nothing else), use of a PO structure will prime subsequent production of PO structures, and the PO structure will remain activated until a DO structure is produced. Under this account, the priming effect should not be affected by whether other, unrelated, structures are produced between production of the prime and production of the target.

Alternatively, activation of a procedure may decay after use, irrespective of whether another structure that can express the same message is produced. This account predicts that use of a $\mathrm{PO}$ structure will temporarily increase the likelihood of producing a PO structure, but that the priming effect will decay through time (or through the application of any procedures associated with sentence production).

Previous evidence concerning this issue is equivocal. In interviews, Weiner and Labov (1983) found that the occurrence of a passive in the preceding five utterances was a predictor of participants' producing another passive. However, these effects might not reflect syntactic priming, but rather a tendency to use a formal or informal register for an extended period during a conversation. Levelt and Kelter (1982) found that when asked What time do you close? (in Dutch), shop assistants tended to say Five o 'clock; ; but when asked At what time do you close?, they tended to say At five o'clock. However, when the question was followed by another clause and a tag question (because I have to come in specially, do you see), this tendency disappeared. Priming in this experiment might have a lexical source, so it might not serve as evidence against the persistence of syntactic priming. It also involved priming between comprehension and production in a very particular kind of environment (question answering).

The clearest demonstrations of syntactic priming (Bock, 1986, 1989; Bock \& Loebell, 1990; Bock et al., 1992; Pickering \& Branigan, 1998; Potter \& Lombardi, 1998) involve adjacent sentences not embedded in discourse. However, recent work suggests that priming may be long-lasting under some circumstances (Bock, Dell, Griffin, Chang, \& Ferreira, 1996; cf. Bock \& Kroch, 1987). Bock et al. (1996) found priming effects when as many as 10 sentences intervened between prime and target. Participants performed a running recognition memory test in which they indicated whether sentences and pictures were repetitions of earlier ones. They were told to repeat the sentences and describe the pictures as a memory aid. This task clearly emphasizes the importance of memory for sentence form.

Our experiment tested whether priming effects persist over intervening stimuli in a written sentence completion task, a task that does not involve any explicit memory component. Participants complete booklets of sentence fragments that contain prime-target pairs. The prime fragments are designed to induce either a PO completion or a DO completion. The target fragments allow either type of completion. Using this method, Pickering and Branigan (1998) found priming for PO and DO structures under a variety of conditions (e.g., when the prime and target verb differed in tense, aspect, or number). They also found priming when the prime and target fragments contained different verbs, but this effect was smaller than when the verb was repeated.

Our experiment employed prime-target pairs containing exactly the same verb form in prime and target. As in Pickering and Branigan (1998), we used PO- and DO-inducing primes. We manipulated whether the prime and the target were adjacent or were separated by either one or four intervening fragments, which always involved intransitive verbs. We assumed that intransitive fragments would be unlikely to induce completions that involved the application of the same procedures as the experimental fragments.

\section{METHOD}

\section{Participants}

Fifty-four participants from the University of Glasgow community volunteered.

\section{Items}

We constructed 16 sets of items (see Appendix). Each included four intransitive fragments (e.g., Example 2), a prime fragment (e.g., Example $3 a$ or $3 b$ ), and a target fragment (e.g., Example 4):

The accounts clerk laughed heartily ...

The boy laughed...

The moody teenager grumbled...

The bank manager snored...

The woman sent the insurance claim ...

The woman sent the insurance company...

The fan sent ...

In each quartet of intransitive fragments, one fragment included a postverbal adverb (e.g., heartily), and two fragments (not necessarily consecutive) employed the same verb (e.g., laughed). These manipulations were designed to make the intransitive fragments more similar to the prime and target fragments.

The prime and target fragments each contained a dative verb that could appear with both the PO and the DO construction. Prime fragments also contained a postverbal noun phrase. The postverbal noun phrase was designed to be either a plausible patient for the action denoted by the verb, as in $3 \mathrm{a}$, encouraging PO completions (e.g., The woman sent the insurance claim to her lawyer) or a plausible beneficiary, as in $3 \mathrm{~b}$, encouraging DO completions (e.g., The 
woman sent the insurance company details of her accident.). The prime and target fragments employed six verbs. Previous experiments demonstrated reliable priming effects with a wider range of verbs, but these six verbs produced particularly low proportions of other (non-PO and non-DO) completions (Pickering \& Branigan, 1998).

The intransitive, prime, and target fragments appeared in three orders. In the zero intervening fragments conditions, the order was as follows: all four intransitive fragments, prime, and target. In the one intervening fragment conditions, the order was as follows: the first three intransitive fragments, prime, the final intransitive fragment, and target. In the four intervening fragments conditions, the order was as follows: prime, all four intransitive fragments, and target. The intransitive fragments always appeared in the same order in each item. Together with the manipulation of prime fragment, this led to six conditions.

We constructed six lists, each containing only one of the three orders. Each list contained equal numbers of $\mathrm{PO}$ - and DO-inducing items, so that exactly one version of each item appeared in each list plus 32 filler fragments of varied types. We constructed 54 eightpage booklets of 128 fragments. The order of each booklet was individually randomized, with at least one filler between items. Instructions stated that we were interested in what sorts of sentences people produce, and that participants should complete the fragments however they liked, as quickly as possible, in order, and without omitting any fragments.

\section{Procedure}

Participants were randomly assigned to lists and each was given a booklet to complete at his/her own pace. The experiment took about $20 \mathrm{~min}$

\section{Scoring}

For each experimental fragment, the first legible response was scored as a PO, DO, or Other. Prime and target completions were scored as POs if the dative verb was immediately followed by a noun phrase that acted as the patient or theme and then by a prepositional phrase beginning with to that acted as the beneficiary. They were scored as DOs if the verb was immediately followed by a noun phrase that acted as the beneficiary and then by a noun phrase that acted as the patient or theme. Additionally, the dative verb could not form part of a phrasal verb (e.g., handed over in The architect handed the latest plan over to the builder.), on the assumption that complex verbs might be processed differently from simple verbs. A target completion could be scored as a PO or DO only if it had a grammatical alternative in the other category. All other completions were scored as Other. Scoring was based on actual completions. For example, if a participant completed a DO-inducing prime fragment as a $P O$ (e.g., completing The mother gave the baby with to her husband.), it was scored as a PO.

\section{Design and Data Analysis}

Every participant completed 16 target fragments, 8 in each of the two conditions defined by the prime completion factor (PO vs. DO prime completion). Different participants were assigned to the different levels of the intervening fragments factor (zero vs. one vs. four intervening fragments).

As in Pickering and Branigan (1998), our dependent variables were the proportions of $\mathrm{PO}$ and $\mathrm{DO}$ target completions following $\mathrm{PO}$ prime completions, and the proportions of $\mathrm{PO}$ and DO target completions following DO prime completions. In other words, we computed the conditional probabilities of $\mathrm{PO}$ target completions following PO prime completions, DO target completions following $P O$ prime completions, and so on. Calculating the dependent variables in this way allowed for the possibility that different prime completions might differentially affect the proportion of Other target completions.

For each condition, we computed the relevant proportions by dividing the number of target completions in the $\mathrm{PO}$ and DO categories by the total number of target completions (i.e., PO, DO, and Other completions) in that condition. These proportions were calculated for each participant and for each item. Target completion (PO target completion vs. DO target completion) therefore constituted an additional factor. Analyses of variance (ANOVAs) were performed on these data, with separate analyses treating participants $\left(F_{1}\right)$ and items $\left(F_{2}\right)$ as random effects. We treated the prime completion factor as within-participants and within-items, and the intervening fragments factor as between-participants but withinitems.

\section{RESULTS}

Participants produced either a PO or a DO completion for the prime fragment on $87 \%$ of trials; of these, $45 \%$ were PO completions and 55\% were DO completions. For the target fragment in these trials, participants produced $36 \%$ PO completions, $37 \%$ DO completions, and $27 \%$ Other completions. Note that only $2.7 \%$ of trials contained any open-class lexical repetition between prime and target completions.

Three-way analyses of variance (ANOVAs) revealed an interaction of prime and target $\left[F_{1}(1,51)=13.10\right.$, $M S_{\mathrm{e}}=.037, p<.01 ; F_{2}(1,15)=16.51, M S_{\mathrm{e}}=.035, p<$ $.01]$. Table 1 shows that participants produced more target completions that were of the same type (PO or DO) as the prime completions than target completions that were of the alternative type to the prime completions. This result corresponds to the syntactic priming effect. However, this effect was modified by a three-way interaction of prime completion, target completion, and distance $\left[F_{1}(2,51)=3.54, M S_{\mathrm{e}}=.037, p<.05 ; F_{2}(2,30)=\right.$ $\left.3.57, M S_{\mathrm{e}}=.040, p<.05\right]$. Table 1 shows that the syntactic priming effect diminished with increasing distance between prime and target: The priming effect was 19\% when zero fragments intervened, $7 \%$ when one fragment intervened, and $2 \%$ when four fragments intervened.

To explore this further, we conducted two-way ANOVAs separately for the three levels of the intervening fragments factor. When zero fragments intervened, there was a strong preference for producing target completions of the same type as prime completions $\left[F_{1}(1,17)=10.74\right.$,

Table 1

Experimental Results

\begin{tabular}{cccc}
\hline $\begin{array}{c}\text { Intervening } \\
\text { Fragments }\end{array}$ & $\begin{array}{c}\text { Prime } \\
\text { Completion }\end{array}$ & PO & DO \\
\hline Zero & PO & .44 & .31 \\
& DO & .24 & .49 \\
One & PO & .48 & .32 \\
& DO & .35 & .34 \\
Four & PO & .34 & .38 \\
& DO & .31 & .39 \\
\hline
\end{tabular}

Note-PO, prepositional object; $\overline{\mathrm{DO}}$, double object. 
$M S_{\mathrm{e}}=.059, p<.01 ; F_{2}(1,15)=33.00, M S_{\mathrm{e}}=.022, p<$ $.01]$. When one fragment intervened, there was a weak tendency to produce target completions of the same type as prime completions $\left[F_{1}(1,17)=3.31, M S_{\mathrm{e}}=.030, p<\right.$ $\left..09 ; F_{2}(1,15)=2.08, M S_{\mathrm{e}}=.054, p<.17\right]$. When four fragments intervened, there was no significant tendency (both $F_{\mathrm{S}}<1$ )

The three-way ANOVAs also revealed a marginal main effect of prime $\left[F_{1}(1,51)=3.59, M S_{\mathrm{e}}=.010, p<\right.$ $\left..07 ; F_{2}(1,15)=3.92, M S_{\mathrm{e}}=.008, p<.07\right]$, suggesting that participants may have produced more Other target completions after DO prime completions than PO prime completions. No other effects approached significance (all $F_{1} \mathrm{~s}<1$, all $F_{2} \mathrm{~s}<1.75$ ).

\section{DISCUSSION}

Our experiment demonstrates that syntactic priming effects occur in written language production, but that syntactic priming can be short-lived: The priming effect decayed rapidly when fragments intervened between the prime and target fragments. Reliable priming occurred only when the target immediately followed the prime. There was a trend toward a priming effect when one fragment intervened between prime and target, but this was not reliable, and there was no priming effect when four fragments intervened.

Our data cast light on the way in which the residual activation that is assumed to underlie priming decays. In particular, they argue against an account in which activation of a procedure persists until an alternative procedure capable of expressing the same message is employed. In our experiment, the fragments that intervened between the prime and target were intransitive, and participants very rarely produced completions for the (intransitive) intervening fragments that included either a noun phrase and a prepositional phrase or two noun phrases immediately following a verb (such completions occurred on only $2.0 \%$ of the scored trials in the one intervening fragment conditions). Hence it is highly unlikely that when participants completed these intervening fragments, they employed procedures related to the procedures they used when producing $\mathrm{PO}$ or DO target completions. This suggests that decay occurs even when participants do not apply a related procedure between prime and target. Our data are instead consistent with an account in which activation decays rapidly after use.

In this respect, our results appear to conflict with those of Bock et al. (1996). Many differences between our experiments may account for this disparity. For example, our experiment always repeated the verb, whereas Bock et al.'s did not; however, Pickering and Branigan (1998) found larger priming effects when the verb was repeated, and it is highly unlikely that our effects would be shorter lasting for this reason. In addition, although the intervening sentences were intransitives in both our experiment and Bock et al.'s (1996), our task required participants to complete the intransitive fragments with addition ma- terial. We also employed writing rather than speech. If decay in priming is partly due to the passage of time, then the slower speed of writing might make some contribution to the short duration of priming in our experiment.

However, we believe that the most likely explanations for the differences lie in the nature of the tasks employed. Our experiment employed sentence completion rather than sentence repetition and picture description. One difference between the two methods is that the prime sentences in the sentence completion task are partly generated by the participants themselves; in the sentence repetition and picture description paradigm, participants simply repeat prime sentences that are provided in their entirety. However, if this methodological difference was important, one might have expected a stronger (and hence longer lasting) priming effect in our sentence completion task than in the sentence repetition and picture description paradigm, contrary to the actual pattern of results. A further difference is that sentence completion may emphasize conceptual-level processing, since participants have to generate a state of affairs that they wish to communicate, whereas in picture description, participants are provided with a state of affairs to communicate. Picture description may therefore emphasize other aspects of production, such as syntactic encoding. Perhaps more importantly, Bock et al.'s (1996) experiment was presented to participants as a running memory experiment. It required participants to remember sentences in order to be able to state whether they had seen those precise sentences before. This method clearly emphasizes memory for sentence form. In contrast, participants in our experiment would gain no benefit from remembering earlier sentences (and the lack of lexical repetition between prime and target completions suggested that they did not do so). Note also that Bock (1986) demonstrated priming with a slightly different task, in which participants studied a set of sentences and pictures and were subsequently tested for recall in a separate session. In this task, participants had no motivation to memorize the priming stimuli, which were encountered only during the test phase. However, this task still requires sentences to be compared with those encoded in memory, and hence still emphasizes the memory component.

Our results suggest that in written completion experiments, priming between consecutive completions is unlikely to be affected by earlier completions. This suggests that the written completion technique is highly versatile and can be employed in experiments containing a relatively small number of filler fragments. As such, our finding has implications for the common use of sentence completion tasks in norming stimuli for sentence comprehension experiments (e.g., Trueswell, 1996; Traxler, Pickering, \& Clifton, 1998).

Our results can be incorporated into the model developed by Pickering and Branigan (1998). They suggested that priming can be explained in terms of activation within the mental lexicon. Following Kempen and Huijbers (1983), Levelt, Roelofs, and Meyer (1999; cf. Roe- 
lofs, 1992, 1993) proposed that the entries in the mental lexicon are represented at two levels: a syntactic level, called the lemma stratum, and a morphophonological level, called the form stratum. Pickering and Branigan extended the model of the lemma stratum to include further syntactic information. Specifically, they argued that lemma nodes (roughly corresponding to an uninflected form of a word, as in give) are linked to (1) combinatorial nodes that are activated when particular syntactic structures are produced and (2) nodes specifying word category (e.g., verb) and nodes specifying grammatical features (e.g., present tense). Producing a word activates associated nodes at the lemma stratum. For example, producing the word gives as part of the sentence The man gives the dog a bone. involves activation of the lemma give, the feature nodes for third person, singular, present tense, and so on, and the combinatorial node associated with the DO construction. In contrast, producing gives as part of the sentence The man gives a bone to the dog. activates the combinatorial node associated with the PO construction instead. As in our present experiment, Pickering and Branigan did not consider whether these combinatorial nodes are activated only when participants are producing sentences containing two postverbal arguments, or whether they might also be activated when participants are producing sentences involving at least one nonargument (e.g.. The boy sang the song in the bath.).

Activation of these nodes (and the links between them) gradually decays, but does not disappear immediately. These nodes are therefore at an advantage in the production of a subsequent sentence. Our present results suggest that this decay is fairly rapid and automatic, and is not dependent on the activation of other nodes that can be used to express the same message. Thus we argue that combinatorial nodes have a baseline level of activation, temporarily raise this level following use of a particular construction, and then decay rapidly back to their baseline level.

\section{REFERENCES}

Bock, J. K. (1986). Syntactic persistence in language production. Cognitive Psychology, 18, 355-387.

BoCK, J. K. (1989). Closed class immanence in sentence production. Cognition, 31, 163-186.

Bock, J. K., Del..., G. S., Griffin, Z. M., Chang, F., \& Ferreira, V. S. (1996, November). Structural priming as implicit learning. Paper presented at the annual meeting of the Psychonomic Society, Chicago.

Bock, J. K., \& KROCH, A. (1987). The isolability of syntactic processing. In G. N. Carlson \& M. K. Tanenhaus (Eds.), Linguistic structure in language processing (pp. 157-196). Dordrecht: Kluwer.

Bock, J. K., \& Loebell, H. (1990). Framing sentences. Cognition, 35, $1-39$.

Bock, J. K., Lofbell, H.. \& Morey, R. (1992). From conceptual roles to structural relations: Bridging the syntactic cleft. Psvchological ReView, 99, 150-171.

Branigan, H. P., Pickering, M. J., Liversedge., S. P., Stewart, A. J., \& URBACH, T. P. (1995). Syntactic priming: Investigating the mental representation of language. Journal of Psvcholinguistic Research, 24, 489-506.

EstivaL, D. (1985). Syntactic priming of the passive in English. Text. $5,7-21$.

Giles, H., \& PowesLand, P. (1975). Speech style and social evaluation. London: Academic Press.

KemPEN, G., \& HuijBers, P. (1983). The lexicalization process in sentence production and naming: Indirect election of words. Cognition, 14, 185-209.

Levelt, W. J. M. (1989). Speaking: From intention to articulation. Cambridge, MA: MIT Press.

Levelt, W. J. M., \& Kelter, S. (1982). Surface form and memory in question answering. Cognitive Psychology, 14, 78-106.

Levelt, W. J. M.. ROELofs, A., \& MEYER, A. S. (1999). A theory of lexical access in speech production. Behavioral \& Brain Sciences, 22, 1 45.

Pickering, M. J., \& Branigan, H. P. (1998). The representation of verbs: Evidence from syntactic priming in language production. Journal of Memory \& Language, 39, 633-651.

Potter, M. C., \& Lombardi, L. (1998). Syntactic priming in immediate recall of sentences. Journal of Memory \& Language, 38, 265-282.

RoELOFs, A. (1992). A spreading-activation theory of lemma retrieval in speaking. Cognition, 42, 107-142.

RoElOFs. A. (1993). Testing a non-decompositional theory of lemma retrieval in speaking: Retrieval of verbs. Cognition, 47, 59-87.

SCHENKEIN, J. (1980). A taxonomy for repeating action sequences in natural conversation. In B. Butterworth (Ed.), Language production (Vol. 1, pp. 21-47). London: Academic Press

TANnFn, D. (1989). Talking voices: Repetition, dialogue and imagery in conversational discourse. Cambridge: Cambridge University Press.

Traxier, M. J., Pickeringi, M. J., \& Clifton, C., JR. (1998). Syntactic ambiguity resolution is not a form of lexical ambiguity resolution. Journal of Memory \& Language, 39, 558-592.

TrueswelL, J. C. (1996). The role of lexical frequency in syntactic ambiguity resolution. Journal of Memory \& Language, 35, 566-585.

WFINER, E. J., \& LABOV, W. (1983). Constraints on the agentless passive. Journal of Linguistics, 19, 29-58.

\section{APPENDIX \\ Experimental Items}

Each item is presented in the following order: intransitive fragments, prime, target. The noun phrase before the slash occurred in the $\mathrm{PO}$-inducing condition; the noun phrase after the slash occurred in the DO-inducing condition.

1. The accounts clerk laughed heartily. The boy laughed. The moody teenager grumbled. The bank manager snored. The woman sent the insurance claim/the insurance company. The fan sent.

2. The Hollywood producer fainted. The receptionist fainted. The dog barked repeatedly. The old man sulked. The captain gave the shiny medal/the old sailor. The bus driver gave.

3. The lecturer vanished. The ghost vanished suddenly. The rambler strode. The campfire blazed. The swimmer loaned the towel/the diver. The draftsman loaned.

4. The volcano erupted. The schoolchild slipped. The clunisy footballer slipped. The monkeys chattered incessantly. The builder lent the plans/the surveyor. The hairdresser lent.

5 . The dining-room table collapsed. The inspector frowned. The annoying actor frowned. The happy tourist smiled broadly. The lecturer gave the book/the student. The shopkeeper gave.

6. The policeman shivered. The male model coughed. The patient coughed twice. The lion growled. The blackmailer posted the sleazy photos/the sleazy journalist. The lonely sailor posted. 


\section{APPENDIX (Continued)}

7. The ice melted slowly. The tall tree swayed. The TV presenter smirked. The prisoner smirked. The courier handed the package/the receptionist. The child handed.

8. The Oscar-winning actress shrieked. The lonely wolf howled. The elderly woman died. The soldier died yesterday. The nurse showed the chart/the doctor. The jeweller showed.

9. The clown chuckled. The bee buzzed. The baby chuckled happily. The light flickered. The spy sold the stolen documents/the foreign diplomat. The shop assistant sold.

10. The visitor sneezed once. The twig snapped. The child sneezed. The student daydreamed. The millionaire loaned the valuable painting/the national museum. The explorer loaned.

11. The sleepy dog yawned. The schoolteacher hiccuped often. The rude shopkeeper yawned. The bonfire smoldered. The car salesman lent the new car/the young couple. The forest ranger lent.

12. The cat purred softly. The climber grimaced. The parrot squawked. The injured athlete grimaced. The racing driver showed the torn overall/the helpful mechanic. The patient showed.
13. The compost decayed. The unfriendly lawyer coughed. The nervous horse twitched. The trainee coughed nervously. The mother gave the expensive toy/the whining child. The air hostess gave.

14. The salesman smiled. The security guard panicked today. The diamond ring sparkled. The walker panicked. The secretary sent the memo/the manager. The boyfriend sent.

15. The pirate sneered. The shop assistant blushed immediately. The doctor snored. The consultant sneered. The booking clerk posted the cheapest tickets/the young fan. The serial killer posted.

16. The temperamental chef shouted. The bored student yawned. The elephant trumpeted loudly. The fashion designer shouted. The bank manager handed the money/the customer. The junior surgeon handed.

(Manuscript received June 24, 1998 revision accepted for publication December 20, 1998.) 